\title{
Optimasi Pendapatan Pembuatan Spanduk dan Baliho Menggunakan Metode Simpleks (Studi Kasus: Usaha Percetakan Shiau Printing)
}

\author{
Matheus Supriyanto Rumetna ${ }^{1, *}$, Otniel ${ }^{1}$, Friendly Litaay ${ }^{1}$, Carlie Sibarani $^{1}$, Ruben Tahrin ${ }^{1}$, Tirsa Ninia Lina ${ }^{1}$, \\ Ratna Rosmauli Pakpahan ${ }^{2}$ \\ ${ }^{1}$ Fakultas Ilmu Komputer, Program Studi Sistem Informasi, Universitas Victory Sorong, Sorong, Indonesia \\ ${ }^{2}$ Fakultas Ilmu Sosial, Program Studi Administrasi Publik, Universitas Victory Sorong, Sorong, Indonesia \\ Email: 1,*matheus.rumetna@ gmail.com, ${ }^{2}$ otniel.oktaviani97@ gmail.com, ${ }^{3}$ friendlylitaay23@ gmail.com, \\ 4pandapotan.carlie86@gmail.com, 5rubentahrin17@gmail.com, ${ }^{6}$ tirsawp@gmail.com \\ Email Penulis Korespondensi: matheus.rumetna@gmail.com \\ Submitted 09-01-2020; Accepted 21-01-2020; Published 26-04-2020
}

\begin{abstract}
Abstrak
Shiau Printing merupakan salah satu usaha yang bergerak di bidang percetakan. Usaha ini sering mengalami masalah optimasi produksi yakni dalam hal menentukan keuntungan maksimum dari dua jenis produk yang dihasilkan yaitu spanduk dan baliho. Kendala yang dihadapi berupa keterbatasan sumber daya produksi, seperti bahan flexi. Masalah ini dapat diselesaikan dengan menerapkan linear programming menggunakan metode simpleks dan kemudian diuji menggunakan aplikasi POM-QM for Windows. Berdasarkan hasil perhitungan yang telah dilakukan ditarik keputusan bahwa Shiau Printing dapat memperoleh pendapatan maksimum sebesar Rp.15.000.000-,/bulan.
\end{abstract}

Kata Kunci: Optimasi, Linear Programming, Metode Simpleks, POM-QM

\section{Abstract}

Shiau Printing is one of the businesses engaged in printing. This business often experiences production optimization problems, namely in terms of determining the maximum profit from the two types of products produced, namely banners and billboards. Constraints faced in the form of limited production resources, such as flexi materials. This problem can be solved by implementing linear programming using the simplex method and then testing it using the POM-QM application for Windows. Based on the results of calculations that have been made, a decision was drawn that the Shiau Printing could obtain a maximum income of IDR 15,000,000 -, / month.

Keywords: Optimization, Linear Programming, Simplex Method, POM-QM

\section{PENDAHULUAN}

Saat ini sudah banyak orang yang mempromosikan jasa, usaha dan bahkan promosikan diri melalui media cetak, baik itu menggunakan spanduk, baliho, dan sebagainya. Hal ini menyebabkan banyak orang yang berlomba membuka usaha di bidang percetakan. Salah satu contoh usaha yang bergerak di bidang percetakan yaitu Shiau Printing. Usaha percetakan ini beralamat di jalan Bima Km.10 Kota Sorong Papua Barat. Usaha ini juga sering mengalami masalah optimasi produksi yakni dalam hal menentukan keuntungan maksimum dari dua jenis produk yang dihasilkan yaitu spanduk dan baliho. Kendala yang dihadapi berupa keterbatasan sumber daya produksi seperti bahan flexi.

Salah satu metode yang dapat digunakan untuk menyelesaikan masalah optimasi produk adalah metode Simpleks[1],[2]. Metode Simpleks merupakan salah satu prosedur yang paling luas penggunaannya untuk pemecahan persoalan Pemrograman Linier (PL). PL adalah metode optimasi untuk menemukan nilai optimum dari fungsi tujuan linier pada kondisi pembatasan-pembatasan (constraints) tertentu [3],[4],[5]. Pembatasan-pembatasan tersebut biasanya keterbatasan yang berkaitan dengan sumber daya seperti bahan mentah, uang, waktu, tenaga kerja, dll.

Persoalan PL dapat ditemukan pada berbagai bidang dan dapat digunakan untuk membantu membuat keputusan untuk memilih suatu alternatif yang paling tepat dan pemecahan yang paling baik (the best solution). PL memiliki tiga hal penting [6],[7],[8], yaitu:

1) Variabel keputusan (decision variables): $\mathrm{x} 1, \mathrm{x} 2, \ldots, \mathrm{xn}$ merupakan variabel yang dipilih menjadi keputusan berdasarkan nilainya.

2) Fungsi tujuan (objective function): $Z=f(x 1, x 2, \ldots, x n)$ merupakan fungsi yang akan dioptimasi (dimaksimumkan atau diminimumkan).

3) Pembatasan (constraints): gi( $x 1, x 2, \ldots, x n) \leq b i$ adalah pembatasan-pembatasan yang harus dipenuhi.

Penelitian ini dilakukan dengan memanfaatkan teknologi informasi yaitu penggunaan aplikasi POM-QM untuk memperkirakan keuntungan maksimum yang diperoleh dari setiap produksi yang dilakukan oleh percetakan Shiau Printing dalam jangka waktu satu bulan dengan cepat dan tepat, sehingga memiliki perkiraan perhitungan yang akurat.

\section{METODE PENELITIAN}

Langkah-langkah yang dilakukan dalam penelitian ini adalah sebagai berikut [8],[9],[10],[11]:

1) Identifikasi Masalah

Masalah yang dihadapi adalah optimasi produksi yakni dalam hal menentukan keuntungan maksimum dari dua jenis produk yang dihasilkan yaitu spanduk dan baliho. Kendala yang terjadi yaitu keterbatasan bahan baku flexi karena bahan baku ini hanya diproduksi di Jawa.

2) Pemilihan Model Pemecahan Masalah 
Seperti yang diijelaskan sebelumnya bahwa dalam penelitian ini menggunakan model matematis PL yaitu penerapan metode simpleks yang kemudian didukung oleh aplikasi POM-QM guna memastikan keakuratan hasil yang diperoleh dari perhitungan manual yang dilakukan sebelumnya.

3) Pengumpulan Data

Pengumpulan data menggunakan teknik wawancara yang dilakukan dengan pemilik usaha percetakan Shiau Printing, berdasarkan fakta-fakta yang terjadi. Data yang dibutuhkan dalam penelitian ini berupa bahan baku produksi, tenaga kerja yang dimiliki, produksi yang dihasilkan, jumlah produksi, dan keuntungan produk per spanduk dan baliho.

4) Pengolahan Data dan Analisis

Pengolahan data dan analisis mengunakan metode simpleks pada PL dengan aplikasi POM-QM.

5) Implementasi Model

Tahap implementasi model adalah mempersiapkan model matematik PL untuk permasalahan optimasi produksi. Pemodelan PL dilakukan dengan mengidentifikasi variabel keputusan, fungsi tujuan dan fungsi-fungsi kendala (constraint).

6) Evaluasi Hasil

Evaluasi hasil dilakukan dengan menganalisis hasil analisis PL yang dihasilkan oleh aplikasi POM-QM pada langkah sebelumnya. Evaluasi hasil juga dilakukan dengan membandingkan antara hasil penelitian dengan kondisi aktual yang dialami oleh usaha percetakan Shiau Printing.

Langkah-langkah penelitian di atas dapat dilihat dengan jelas pada Gambar 1.

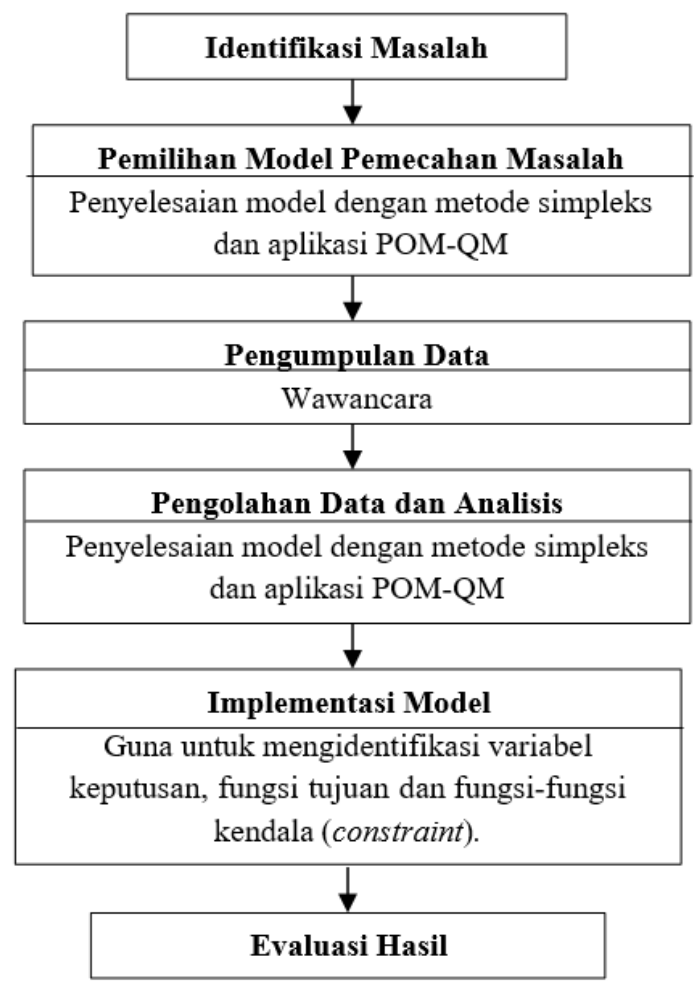

Gambar 1. Flowchart Penelitian

\section{HASIL DAN PEMBAHASAN}

Berdasarkan hasil wawancara diperoleh data bahwa percetakan Shiau Printing memproduksi spanduk dan baliho dengan menggunakan bahan baku flexi. Dalam memproduksi 1 buah spanduk ukuran 3x1, kapasitas yang tersedia yaitu $180 \mathrm{~m}$, sedangkan untuk memproduksi 1 buah baliho ukuran 2x3, kapasitas yang tersedia yaitu $120 \mathrm{~m}$. Dari data tersebut kemudian dilakukan perhitungan untuk mendapatkan pendapatan maksimum yang diperoleh Shiau Printing selama 1 bulan.

Tabel 1. Jenis produk, laba dan kapasitas

\begin{tabular}{|c|c|c|c|}
\hline \multirow[t]{2}{*}{ Bahan Baku } & \multicolumn{2}{|c|}{ Jenis Produk } & \multirow{2}{*}{$\begin{array}{c}\text { Kapasitas } \\
\text { (meter) }\end{array}$} \\
\hline & Spanduk & Baliho & \\
\hline Flexi & 3 & 0 & 180 \\
\hline Flexi & 0 & 6 & 120 \\
\hline Keuntungan & 150.000 & 300.000 & \\
\hline
\end{tabular}




\subsection{Analisis Data}

Berdasarkan data pada Tabel 1 diperoleh penyelesaian PL sebagai berikut:

Menentukan variabel dimana spanduk $=X_{1}$ dan baliho $=X_{2}$

Fungsi tujuan $\mathrm{Z}=150.000 \mathrm{X}_{1}+300.000 \mathrm{X}_{2}$

Fungsi kendala $3 \mathrm{X}_{1} \leq 180$

Langkah-langkah :

$$
+6 X_{2} \leq 120
$$

1) Fungsi tujuan diubah menjadi fungsi implisit yaitu menggeser elemen dari sebelah kanan ke sebelah kiri, sehingga fungsi tujuan ini menjadi:Fungsi Tujuan :

$Z=150.000 X_{1}+300.000 X_{2}=>Z-150.000 X_{1}-300.000 X_{2}=0$

Fungsi batasan diubah dengan memberikan variable slack yang berguna untuk mengetahui batasan-batasan dalam kapasitas dengan menambah variabel tambahan menjadi:

$3 \mathrm{X}_{1} \leq 180=3 \mathrm{X}_{1} \quad+\mathrm{X}_{3} \quad=180$

$6 \mathrm{X}_{2} \leq 120 \Rightarrow 6 \mathrm{X}_{2}+\mathrm{X}_{4}=120$

2) Menyusun persamaan ke dalam tabel, seperti pada Tabel 2 berikut.

Tabel 2. Formulasi

\begin{tabular}{cccccccc}
\hline $\begin{array}{c}\text { Variabel } \\
\text { Dasar }\end{array}$ & $\mathrm{Z}$ & $\mathrm{X} 1$ & $\mathrm{X} 2$ & $\mathrm{X} 3$ & $\mathrm{X} 4$ & $\mathrm{NK}$ & Index \\
\hline $\mathrm{Z}$ & 1 & -150 & -300 & 0 & 0 & 0 & 0 \\
$\mathrm{~S} 1$ & 0 & 3 & 0 & 1 & 0 & 180 & 33 \\
$\mathrm{~S} 2$ & 0 & 0 & 6 & 0 & 1 & 120 & 33 \\
\hline
\end{tabular}

3) Memilih kolom kunci

Dimana kolom kunci mempunyai nilai pada baris $\mathrm{Z}$ yang bernilai negative dengan angka terbesar, seperti pada Tabel 3.

Tabel 3. Kolom Kunci

\begin{tabular}{|c|c|c|c|c|c|c|c|}
\hline $\begin{array}{c}\text { Variabel } \\
\text { Dasar }\end{array}$ & $\mathrm{Z}$ & $\mathrm{X} 1$ & $\mathrm{X} 2$ & $\mathrm{X} 3$ & $\mathrm{X} 4$ & NK & Index \\
\hline $\mathrm{Z}$ & 1 & -150 & -300 & 0 & 0 & 0 & \\
\hline $\mathrm{S} 1$ & 0 & 3 & 0 & 1 & 0 & 180 & \\
\hline $\mathrm{S} 2$ & 0 & 0 & 6 & 0 & 1 & 120 & \\
\hline
\end{tabular}

Karena $\mathrm{X}_{2}$ merupakan kolom yang mempunyai angka negatif paling tinggi yaitu -300 maka kolom $\mathrm{X}_{2}$ merupakan kolom pivot dan $\mathrm{X}_{2}$ merupakan variabel masuk.

4) Memilih baris kunci

Baris kunci adalah baris yang memiliki nilai index terkecil, lihat Tabel 4.

Tabel 4. Baris Kunci

\begin{tabular}{cccccccc}
\hline $\begin{array}{c}\text { Variabel } \\
\text { Dasar }\end{array}$ & $\mathrm{Z}$ & $\mathrm{X} 1$ & $\mathrm{X} 2$ & $\mathrm{X} 3$ & $\mathrm{X} 4$ & $\mathrm{NK}$ & Index \\
\hline $\mathrm{Z}$ & 1 & -150 & -300 & 0 & 0 & 0 & \\
$\mathrm{~S} 1$ & 0 & 3 & 0 & 1 & 0 & 180 & $\sim$ \\
$\mathrm{S} 2$ & 0 & 0 & 6 & 0 & 1 & 120 & 20 \\
\hline \multicolumn{7}{c}{ Baris Kunci }
\end{tabular}

Index merupakan hasil pembagian antara nilai kanan (NK) dengan nilai kolom kunci.

Rasio pembagian nilai paling kecil adalah baris S2 yang merupakan baris pivot atau variabel keluar, elemen pivot adalah 6 .

5) Mengubah nilai-nilai baris kunci.

Dengan cara membaginya dengan angka kunci.

Baris baru kunci $=$ Baris Kunci : Angka kunci

Nilai baris kunci diubah dengan cara dibagim dengan angka kunci, yaitu:
a. $0 / 6=0$
d. $0 / 6=0$
b. $0 / 6=0$
e. $1 / 6=0.166$
c. $6 / 6=1$
f. $120 / 6=20$ 
Iterasi 1 hasil pembagian dimasukkan pada baris baru yaitu $\mathrm{X}_{1}$ dimana baris $\mathrm{S} 1$ diubah menjadi baris $\mathrm{X}_{1}$, perhatikan Tabel 5 .

Tabel 5. Perubahan baris kunci

\begin{tabular}{cccccccc}
\hline $\begin{array}{c}\text { Variabel } \\
\text { Dasar }\end{array}$ & $\mathrm{Z}$ & $\mathrm{X} 1$ & $\mathrm{X} 2$ & $\mathrm{X} 3$ & $\mathrm{X} 4$ & $\mathrm{NK}$ & Index \\
\hline $\mathrm{Z}$ & 1 & -150 & -300 & 0 & 0 & 0 & \\
$\mathrm{~S} 1$ & 0 & 3 & 0 & 1 & 0 & 180 & $\sim$ \\
S2 & 0 & 0 & 1 & 0 & 0.166 & 20 & 20 \\
\hline
\end{tabular}

Berdasarkan tabel tersebut terdapat perubahan angka-angka pada baris S2 setelah dilakukan perhitungan.

6) Mengubah nilai selain pada baris kunci sehingga nilai-nilai kolom kunci (selain baris kunci) $=0$

Baris kunci = baris lama (koefisien angka kolom kunci $\mathrm{x}$ nilai baris baru kunci).

Keterangan :

a) Baris lama $=$ baris $\mathrm{Z}$ dan baris $\mathrm{S} 1$

b) Koefisien per kolom kunci = nilai dari angka kolom kunci yaitu -300 dan 0 .

c) Nilai baris kunci $=$ nilai dari baris $\operatorname{kunci} \operatorname{baru}\left(\mathrm{X}_{2}\right)$

Perhitungan nilai baris :

Baris Z

Baris Lama $\quad\left[\begin{array}{llllll}-150 & -300 & 0 & 0 & 0\end{array}\right]$

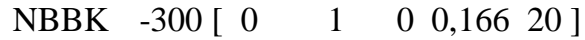

Baris Baru $\begin{array}{lllll}-150 & 0 & 0 & 50 & 6.00\end{array}$

Baris kunci $=$ baris lama (koefisien angka kolom kunci $*$ nilai baris baru kunci)

a. $-150-(-300 * 0)=-150$

b. $-300-(-300 * 1)=0$

c. $0-(-300 * 0)=0$

d. $0-(-300 * 0,166)=50$

e. $0-(-300 * 20)=6000$

Maka dari hasil perhitugan nilai baris baru Z adalah -150,0,0,50,6000

Baris S1

Baris Lama $\left[\begin{array}{lllll}3 & 0 & 1 & 0 & 180\end{array}\right]$

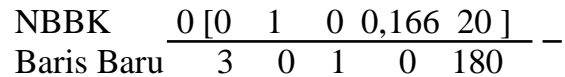

Baris kunci $=$ baris lama (koefisien angka kolom kunci $\mathrm{x}$ nilai baris baru kunci)
a. $3-(0 * 0)=3$
b. $0-(0 * 1)=0$
c. $\quad 1-(0 * 0)=1$
d. $\quad 0-(0 * 0,166)=0$
e. $180-(0 * 20)=180$

Maka dari hasil perhitugan nilai baris baru S1 adalah 3,0,1,0,150.

Memasukkan hasil perhitungan di atas ke dalam tabel Hasil perhitungan.

Tabel 6. Hasil perhitungan

\begin{tabular}{cccccccc}
\hline $\begin{array}{c}\text { Variabel } \\
\text { Dasar }\end{array}$ & $\mathrm{Z}$ & $\mathrm{X} 1$ & $\mathrm{X} 2$ & $\mathrm{X} 3$ & $\mathrm{X} 4$ & $\mathrm{NK}$ & Index \\
\hline $\mathrm{Z}$ & 1 & -150 & 0 & 0 & 50 & 6000 & \\
$\mathrm{~S} 1$ & 0 & 3 & 0 & 1 & 0 & 180 & \\
$\mathrm{~S} 2$ & 0 & 0 & 1 & 0 & 0.166 & 20 & \\
\hline
\end{tabular}

Hasil perhitungan yang ditunjukan pada Tabel 6 masih memerlukan perbaikan yang dilakukan secara iterasi sampai baris Z tidak memiliki nilai negatif. Perbaikan yang dilakukan dimulai dengan cara memilih kolom kunci (lihat Tabel 7). Kemudian memilih baris kunci (lihat Tabel 8).

Tabel 7. Memilih kolom kunci baru

\begin{tabular}{llllllll}
\hline $\begin{array}{l}\text { Variabel } \\
\text { Dasar }\end{array}$ & $\mathrm{Z}$ & $\mathrm{X} 1$ & $\mathrm{X} 2$ & $\mathrm{X} 3$ & $\mathrm{X} 4$ & $\mathrm{NK}$ & Index \\
\hline
\end{tabular}




\begin{tabular}{ccccccc}
\hline $\mathrm{Z}$ & 1 & -150 & 0 & 0 & 50 & 6000 \\
$\mathrm{~S} 1$ & 0 & 3 & 0 & 1 & 0 & 180 \\
$\mathrm{~S} 2$ & 0 & 0 & 1 & 0 & 0.166 & 20 \\
\hline
\end{tabular}

Tabel 8. Memilih baris kunci baru

\begin{tabular}{cccccccc}
\hline $\begin{array}{c}\text { Variabel } \\
\text { Dasar }\end{array}$ & $\mathrm{Z}$ & $\mathrm{X} 1$ & $\mathrm{X} 2$ & $\mathrm{X} 3$ & $\mathrm{X} 4$ & $\mathrm{NK}$ & Index \\
\hline $\mathrm{Z}$ & 1 & -150 & 0 & 0 & 50 & 6000 & \\
$\mathrm{~S} 1$ & 0 & 3 & 0 & 1 & 0 & 180 & 60 \\
$\mathrm{~S} 2$ & 0 & 0 & 1 & 0 & 0.166 & 20 & $\sim$ \\
\hline
\end{tabular}

Mengubah nilai pada baris kunci.
a. $0 / 3=0$
d. $1 / 3=0.333$
b. $3 / 3=1$
e. $0 / 6=0$
c. $0 / 3=0$
f. $180 / 3=60$

Iterasi 2 hasil pembagian dimasukkan pada baris baru yaitu X1 dimana baris S1 diubah menjadi baris X1, perhatikan Tabel 9 .

Tabel 9. Perubahan baris kunci baru

\begin{tabular}{cccccccc}
\hline $\begin{array}{c}\text { Variabel } \\
\text { Dasar }\end{array}$ & $\mathrm{Z}$ & $\mathrm{X} 1$ & $\mathrm{X} 2$ & $\mathrm{X} 3$ & $\mathrm{X} 4$ & $\mathrm{NK}$ & Index \\
\hline $\mathrm{Z}$ & 1 & -150 & 0 & 0 & 50 & 6000 & \\
$\mathrm{~S} 1$ & 0 & 3 & 0 & 1 & 0 & 180 & 60 \\
$\mathrm{~S} 2$ & 0 & 0 & 1 & 0 & 0.166 & 20 & $\sim$ \\
\hline
\end{tabular}

Perhitungan nilai baris :

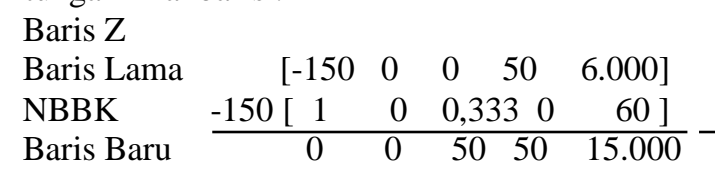

Baris kunci $=$ baris lama (koefisien angka kolom kunci $*$ nilai baris baru kunci)
a. $-150-(-150 * 1)=0$
b. $0-(-150 * 0)=0$
c. $0-(-150 * 0,333)=50$
d. $\quad 50-(-150 * 0)=50$
e. $6000-(-150 * 60)=15.000$

Maka dari hasil perhitugan nilai baris baru $\mathrm{Z}$ adalah 0, 0, 50, 50, 15.000 .

Baris S2

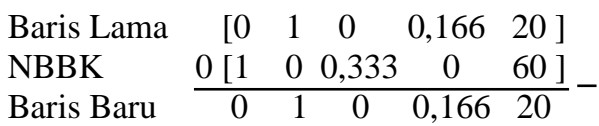

Baris kunci $=$ baris lama (koefisien angka kolom kunci $*$ nilai baris baru kunci)
a. $0-(0 * 1)=0$
b. $\quad 1-(0 * 0)=1$
c. $0-(0 * 0)=0$
d. $\quad 0,166-(0 * 0,333)=0,166$
e. $20-(0 * 60)=20$

Maka dari hasil perhitugan nilai baris baru S2 adalah 0, 1, 0, 0,333.

Memasukkan hasil perhitungan di atas ke dalam tabel Hasil optimasi perhitungan.

Tabel 10. Hasil optimasi perhitungan

\begin{tabular}{cccccccc}
\hline $\begin{array}{c}\text { Variabel } \\
\text { Dasar }\end{array}$ & $\mathrm{Z}$ & $\mathrm{X} 1$ & $\mathrm{X} 2$ & $\mathrm{X} 3$ & $\mathrm{X} 4$ & $\mathrm{NK}$ & Index \\
\hline $\mathrm{Z}$ & 1 & 0 & 0 & 50 & 50 & 15000 & \\
$\mathrm{~S} 1$ & 0 & 1 & 0 & 0.333 & 0 & 180 & \\
$\mathrm{~S} 2$ & 0 & 0 & 1 & 0 & 0.166 & 20 & \\
\hline
\end{tabular}


Berdasarkan Tabel 10 di atas tidak terdapat nilai negatif pada baris Z, maka pendapatan maksimum yang diperoleh percetakan Shiau Printing per bulan sebesar Rp.15.000.000.

\subsection{Pengujian Hasil Optimasi Menggunakan Aplikasi POM-QM}

Berdasarkan hasil perhitungan manual yang telah didapat akan dilakukan pengujian menggunakan aplikasi POM-QM.

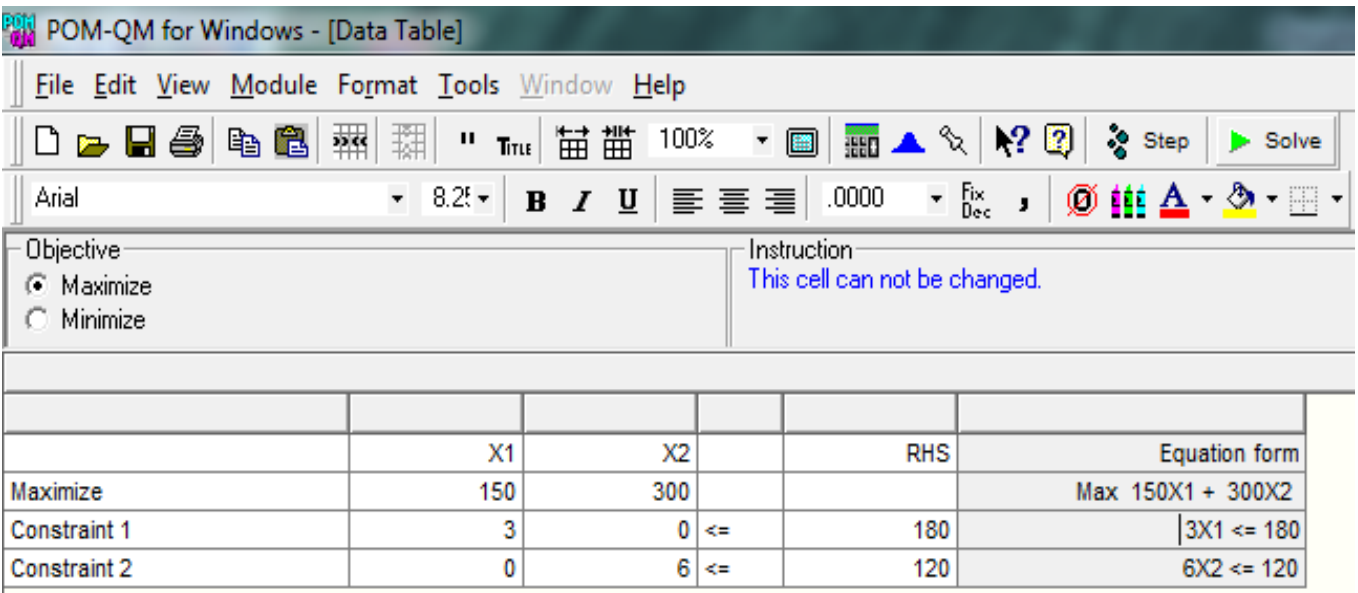

Gambar 2. Tampilan masukkan data produksi

Setelah data selesai dimasukkan (lihat Gambar 2) kemudian pilih tombol solve lalu pilih menu Iterations. Maka akan diperoleh solusi pemecahan persoalan linear programming dengan metode Simpleks (lihat Gambar 3).

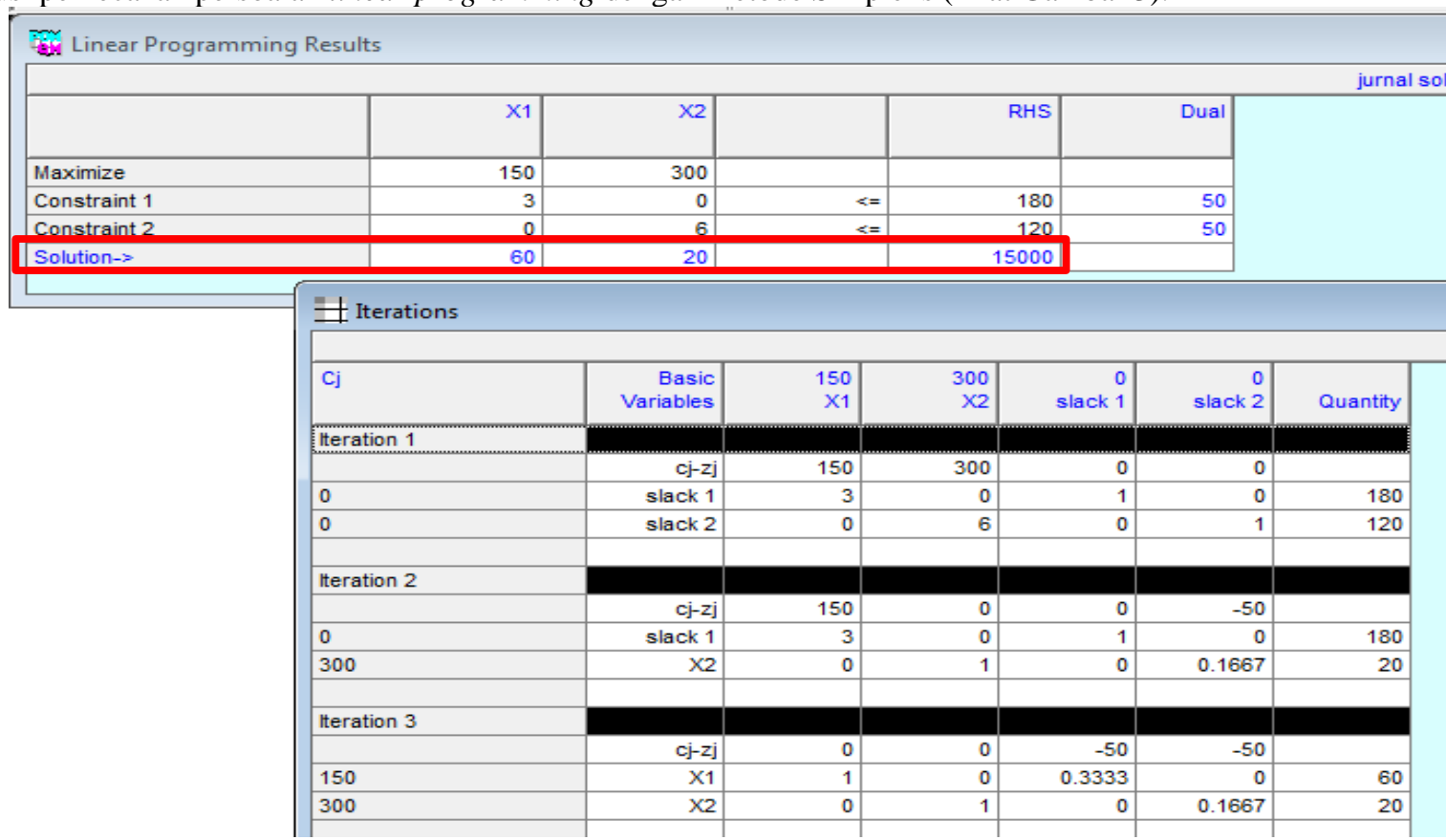

Gambar 3. Tampilan hasil pemecahan masalah

Hasil pengujian menunjukkan bahwa penerapan PL dengan menggunakan aplikasi POM-QM dalam optimasi usaha percetakan Shiau Printing sangat membantu dalam menghitung keuntungan maksimum dari keterbatasan sumber daya yang dimiliki. Dengan metode simpleks, keuntungan maksimal yang dapat diperoleh percetakan Shiau Printing yaitu Rp. 15.000 .000 ,- per produksi spanduk dan baliho dalam jangka 1 bulan. Hasil ini juga sama dengan hasil perhitungan manual.

\section{KESIMPULAN}

Adapun kesimpulan yang dapat ditarik yaitu:

1) Berdasarkan proses perhitungan yang telah dilakukan diperoleh keuntungan maksimal sebesar Rp. 15.000.000,-per bulannya.

2) Metode simpleks dapat dijadikan acuan dalam proses pengambilan keputusan, karena dapat memperkirakan keuntungan dari hasil produksi yang ada. 
3) Aplikasi POM-QM dapat membantu dalam meningkatkan perhitungan PL menggunakan metode simpleks secara cepat, tepat dan efisien.

\section{REFERENCES}

[1] Y. Isabella, H. Cahyadi, and R. Respati, "PEMILIHAN RUTE TERPENDEK DENGAN MENGGUNAKAN SOFTWARE POM QM FOR WINDOWS 3 (STUDI KASUS JALAN SANGGA BUANA 2- UNIVERSITAS MUHAMMADIYAH PALANGKARAYA)," Media Ilm. Tek. Sipil, vol. 4, no. 1, pp. 124-132, 2016.

[2] L. Sarmin et al., "PENERAPAN METODE SIMPLEKS UNTUK MENGHITUNG KEUNTUNGAN MAKSIMUM PADA PENGRAJIN GELANG BESI PUTIH DI PASAR REMU SORONG,” J. KUADAS, vol. 1, no. 2, pp. 1-7, 2018.

[3] Z. Nasution et al., "PENERAPAN METODE SIMPLEKS UNTUK MENGANALISA PERSAMAAN LINIER DALAM MENGHITUNG KEUNTUNGAN MAKSIMUM,” J. Ris. Komput., vol. 3, no. 4, pp. 42-48, 2016.

[4] M. S. Rumetna, T. N. Lina, T. Aponno, A. Palisoa, and F. Singgir, "Penerapan Metode Simpleks Dan Software POM- QM Untuk Optimalisasi Hasil Penjualan Pentolan Bakso," Ilm. Manaj. Inform. dan Komput., vol. 02, no. 03, pp. 143-149, 2018.

[5] M. Rumetna, Supriyanto et al., "PENERAPAN METODE SIMPLEKS UNTUK MENGHASILKAN KEUNTUNGAN MAKSIMUM PADA PENJUAL BUAH PINANG,”J. Dedication To Papua Community2, vol. 2, no. 1, pp. 75-86, 2019.

[6] Firmansyah, D. J. Panjaitan, M. Salayan, and A. D. Silalahi, "PENGOPTIMALAN KEUNTUNGAN BADAN USAHA KARYA TANI DI DELI SERDANG DENGAN METODE SIMPLEKS,” J. Islam. Sci. Technol., vol. 3, no. 1, pp. 18-28, 2018.

[7] Eliatun and T. Darmansyah, "Pengembangan Perumahan Dengan Desain Konstruksi Di Lahan Basah Pada Wilayah Kota Banjarmasin Menggunakan Riset Operasi,” GRADASI Tek. SIPIL, vol. 2, no. 1, pp. 69-75, 2018.

[8] V. Ngamelubun et al., "Optimalisasi Keuntungan Menggunakan Metode Simpleks Pada Produksi Batu Tela," Ris. Komput., vol. 6 , no. 5, pp. 484-491, 2019.

[9] M. S. Rumetna, T. N. Lina, L. Simarmata, L. Parabang, A. Joseph, and Y. Batfin, "Pemanfaatan POM-QM Untuk Menghitung Keuntungan Maksimum UKM Aneka Cipta Rasa (ACR) Menggunakan Metode Simpleks," in GEOTIK, 2019, pp. 12-22.

[10] Budiyanto, S. Mujiharjo, and S. Umroh, "Maksimalisasi Profit pada Perusahaan Roti Bunda Bakery Menggunakan Metode Simplek," AGROINDUSTRI, vol. 7, pp. 84-98, 2017.

[11] R. Ong et al., "Maksimalisasi Keuntungan Pada Usaha Dagang Martabak Sucipto Menggunakan Metode Simpleks Dan POM-QM," Ris. Komput., vol. 6, no. 4, pp. 434-441, 2019. 